\title{
Programa de Atenção na área de Alcool e outras Drogas (PAAD) ${ }^{\star}$
}

\author{
Artemis Soares Viot Serra $\star \star$

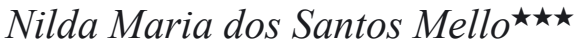 \\ Sônia Marília Matsuda Lessa ${ }^{\star \star \star}$ \\ Hugo Leonardo Rodrigues Soares $\star \star \star \star \star ~$ \\ Hérica Cristina Batista Gonçalves ${ }^{\star \star \star \star \star \star ~}$
}

Palavras-chaves: Dependência Química; Equipe Multidisciplinar; Psicologia Hospitalar

Introdução: O Hospital Estadual Rocha Faria, localizado na Zona Oeste do Rio de Janeiro, presta atendimento emergencial à população, principalmente na área de trauma.. Por ser uma Unidade de emergência atende um grande número de pessoas vítimas de acidente de trânsito, pelo consumo de álcool, e também portadores de doenças decorrentes de seu uso abusivo. Observa-se grande incidência de usuários dependentes de álcool e ou outras drogas na emergência e enfermarias. A partir deste quadro teve inicio o Programa de Atenção na Área de Álcool e outras Drogas (PAAD) que é realizado nesta Unidade, Zona Oeste do Município do Rio de Janeiro e foi construído para atender uma demanda significativa de usuários e familiares que apresentavam questões relacionadas a essa área. Sendo importante destacar que é a única iniciativa de ambulatório especializado para população adulta nesta região. Objetivos: O trabalho vem sendo desenvolvido em uma visão interdisciplinar entre o Serviço Social e a Saúde Mental, com os seguintes objetivos: informar e refletir com a população em geral sobre temas relacionados ao uso indevido de álcool e outras drogas; e oferecer assistência ambulatorial biopsicossocial aos usuários e seus familiares e sensibilizar e mobilizar outros profissionais para inserção no trabalho de prevenção desenvolvido. Metodologia: O modelo de tratamento utilizado é o sócio-cultural, que considera a etiologia do uso de drogas relacionadas ao processo de socialização em um meio social particular, ou seja, utiliza-se de estratégias sócio-culturais focalizadas na pessoa, bem como no ambiente físico e social, visando novas formas de socialização. A grande vantagem deste modelo é que abre a possibilidade de utilizar diferentes formas de intervenção que podem ser

\footnotetext{
^ Trabalho apresentado no I Encontro de Serviço Social da UFRJ em 2009.

$\star \star$ Mestre em Serviço Social pela ESS/UFRJ e assistente social UNIPRAD/CEPRAL/HESFA/ UFRJ e do Hospital Estadual Rocha Faria e membro da Equipe do PAAD.

$\star \star \star$ Assistente Social do Hospital Estadual Rocha Faria da Equipe e membro da Equipe do PAAD.

$\star \star \star \star$ Mestre em Saúde Pública pela USP e Especialista na área de álcool e outras drogas pela UNIFESP, psicóloga do Serviço de Saúde Mental do Hospital Estadual Rocha Faria e membro da Equipe do PAAD.

$\star \star \star \star \star$ Especialista na área de álcool e outras drogas pela UNIFESP, Médico do Serviço de Saúde Mental do Hospital Estadual Rocha Faria e membro da Equipe do PAAD.

$\star \star \star \star \star \star$ Psicóloga, residente de Saúde Mental do Instituto Municipal Philippe Pinel. E-mail: hericacris@yahoo.com.br
} 
propostas para diferentes pessoas. Ao invés de se estabelecer um modelo de tratamento único e fechado propomos a cada usuário a técnica mais adequada ao seu momento visando à adesão ao tratamento, sua continuidade e recuperação. A equipe é constituída de assistentes sociais, psicóloga e psiquiatra. Existe uma importante parceria com membros de Alcoólicos Anônimos. Resultados e conclusões: Neste período de agosto de 2008 a maio de 2009 obtivemos as seguintes freqüências: nos encontros de prevenção 194 participantes da atividade de prevenção, nos grupos semanais 105 usuários, nas abordagens nos leitos 90 internos e os atendimentos psiquiátricos individuais em média de 70 neste período. A partir desses quantitativos podemos avaliar que o trabalho desenvolvido vem encontrando adesão dos usuários, familiares e profissionais, tanto em relação ao trabalho de prevenção como no tratamento. O perfil básico da população atendida é constituído de homens adultos com um reduzido comparecimento de mulheres. Considerando o quantitativo de atendimentos, percebe-se a importância da manutenção deste trabalho neste Hospital de emergência e a necessidade de ampliação da rede de atendimento a esta população que fica e sem opção de tratamento nesta região do Município do Rio de Janeiro. O PAAD como sendo única iniciativa de atendimento na Zona Oeste para adultos na área de álcool e outras drogas na rede pública vem se constituir uma importante iniciativa de acordo com as orientações das políticas publicas do Ministério da Saúde. 